\title{
Microbial community structure in a thermophilic anaerobic hybrid reactor degrading terephthalate
}

Correspondence
Wen-Tso Liu
cveliuwt@nus.edu.sg

Received 29 March 2004

Revised 2 July 2004

Accepted 9 July 2004

\author{
Chia-Lung Chen, ${ }^{1}$ Hervé Macarie, ${ }^{2}$ Ignacio Ramirez, ${ }^{3}$ Alejandro Olmos, ${ }^{3}$ \\ Say Leong Ong, ${ }^{1}$ Oscar Monroy ${ }^{3}$ and Wen-Tso Liu ${ }^{1}$
}

\author{
${ }^{1}$ Department of Civil Engineering, National University of Singapore, Blk E1A, \#07-03, \\ Engineering Drive 2, Singapore 117576 \\ ${ }^{2}$ Laboratoire de Microbiologie, Institut de Recherche pour le Développement (IRD-ex \\ ORSTOM), Universités de Provence et de la Méditerranée, ESIL case 925, 163 Avenue de \\ Luminy, 13288 Marseille cedex 09, France \\ ${ }^{3}$ Departamento de Biotecnología, Universidad Autónoma Metropolitana-Iztapalapa, Av. San \\ Rafael Atlixco 186, Col. Vicentina, 09340 Iztapalapa, DF, Mexico
}

\begin{abstract}
A thermophilic terephthalate-degrading methanogenic consortium was successfully enriched for 272 days in an anaerobic hybrid reactor, and the microbial structure was characterized using terminal RFLPs, clone libraries and fluorescence in-situ hybridization with rRNA-targeted oligonucleotide probes. All the results suggested that Methanothrix thermophila-related methanogens, Desulfotomaculum-related bacterial populations in the Gram-positive low-G + C group, and OP5-related populations were the key members responsible for terephthalate degradation under thermophilic methanogenic conditions except during periods when the reactor experienced heat shock and pump failure. These perturbations caused a significant shift in bacterial population structure in sludge samples taken from the sludge bed but not from the surface of the packing materials. After system recovery, many other bacterial populations emerged, which belonged mainly to the Gram-positive low- $\mathrm{G}+\mathrm{C}$ group and Cytophaga-Flexibacter-Bacteroides, as well as $\beta$-Proteobacteria, Planctomycetes and Nitrospira. These newly emerged populations were probably also capable of degrading terephthalate in the hybrid system, but were out-competed by those bacterial populations before perturbations.
\end{abstract}

\section{INTRODUCTION}

Purified terephthalic acid or PTA (1,4-benzenedicarboxylic acid) is currently used as a raw material in large amounts for manufacturing polyester films, textile fibres and polyethylene terephthalate bottles worldwide (Suresh et al., 2001). During its production, high-strength wastewater, containing terephthalate (TA) as the main component in addition to other organic compounds, is produced and discharged. While various types of anaerobic mesophilic (35$37^{\circ} \mathrm{C}$ ) treatments have been shown to effectively treat the discharged PTA wastewater (Macarie, 2000), thermophilic

Abbreviations: $\mathrm{Bv}$, volumetric organic loading rate; $\mathrm{CFB}$, CytophagaFlexibacter-Bacteroides; COD, chemical oxygen demand; DAPI, 4',6diamidino-2-phenylindole; FISH, fluorescence in situ hybridization; LGC, Gram-positive low-G $+C$ group; HRT, hydraulic retention time; PTA, purified terephthalic acid; SEM, scanning electron microscopy; TA, terephthalate; UASB, upflow anaerobic sludge bed; VSS, volatile suspended solids.

The GenBank/EMBL/DDBJ accession numbers for the 16S rRNA gene sequences reported in this paper are AY297961-AY297969, AY297971-AY297978, AY297980-AY297982, AY297985, AY297987-AY297992 and AY661403-AY661422. $\left(55^{\circ} \mathrm{C}\right)$ anaerobic treatment processes may be an attractive alternative to the mesophilic systems. This is because PTA wastewater is usually generated at $54-60{ }^{\circ} \mathrm{C}$, a temperature close to the optimum for thermophilic methanogenic consortia. Moreover, such consortia are reported to generally have much higher specific organic removal rates than the mesophilic consortia (van Lier et al., 1997). Thus, the anaerobic reactor volume required to treat a certain wastewater flow rate can be significantly smaller under thermophilic rather than mesophilic conditions.

Past studies have suggested that mesophilic TA degradation follows a two-step process through the syntrophic association between fermentative bacterial groups which convert TA to acetate and hydrogen and methanogens which convert acetate and hydrogen to final gaseous products $\left(\mathrm{CH}_{4}\right.$ and $\left.\mathrm{CO}_{2}\right)$ (Fajardo et al., 1997; Kleerebezem et al., 1999a, b; Wu et al., 2001; Qiu et al., 2004). This is because the oxidation of TA to acetate and hydrogen is an endergonic reaction unless coupled to methanogenesis reactions that further convert those intermediates to the final gaseous products (Kleerebezem et al., 1999a). The observation that degradation of TA could be 
inhibited in the presence of acetate or benzoate further supports a hypothesis that the degradation pathway is through decarboxylation via benzoate to acetate and hydrogen (Fajardo et al., 1997; Kleerebezem et al., 1999b). Using culture-dependent methods and molecular techniques, the major fermentative bacterial populations involved in mesophilic methanogenic TA degradation have been identified as being from the $\delta$-Proteobacteria (Wu et al., 2001) and the subcluster Ih of the group 'Desulfotomaculum lineage I' (Qiu et al., 2004). In addition, the syntrophic methanogenic counterparts have been identified as Methanosaeta concilii and members of Methanospirillum and Methanobacteriaceae. These results further support the concept that TA degradation is a twostep process under methanogenic conditions.

Unlike mesophilic methanogenic processes, little is known about the feasibility and microbial consortia for the anaerobic thermophilic treatment of PTA wastewater. An initial attempt by Kleerebezem et al. (1999c) failed to establish a thermophilic methanogenic consortium in a UASB (upflow anaerobic sludge bed) reactor fed with TA as the sole carbon source. This failure was probably attributable to a low number of thermophilic TA-degrading organisms in the original seed sludge and inadequate operational conditions to enrich the microbial consortia. S. Thierry, I. Ramirez, C. Allouche, H. Ferrer \& H. Macarie (unpublished results) successfully demonstrated that all the chemicals present in PTA wastewaters (i.e. terephthalic, phthalic, benzoic, trimellitic and acetic acids), with the exception of $p$-toluic acid, were readily degradable in a laboratory-scale thermophilic hybrid anaerobic reactor (i.e. UASB with pack materials) over a period of 800 days. The highest loading rate achieved $\left(16 \mathrm{~kg} \mathrm{COD} \mathrm{m}^{-3}\right.$ day $^{-1}$ ) was at least comparable to those obtained from full-scale mesophilic systems such as expanded granular sludge bed and internal circulation reactors operated at PTA plants. A good understanding of the thermophilic methanogenic community involved in the TA degradation is necessary in order to facilitate future efforts for full-scale process start-up (good seed sludge selection), to monitor process treatment efficiency and to establish optimal operating conditions. At the moment, the microbial community responsible, which is likely to be different from the mesophilic species (Wu et al., 2001; Qiu et al., 2004), remains unknown. Thus, this study focused on the characterization of microbial community structure and dynamics in a thermophilic methanogenic consortium responsible for TA degradation using various molecular techniques. A laboratory-scale hybrid anaerobic reactor degrading TA-containing wastewater was successfully operated for 272 days and characterized.

\section{METHODS}

Thermophilic anaerobic TA-degrading reactor. A $1 \cdot 2$ litre laboratory-scale hybrid reactor, packed with 69 polypropylene Pall rings (Flexiring, Koch) (total volume, $400 \mathrm{ml}$ ), was used to enrich anaerobic microbial consortia degrading TA under thermophilic conditions. It was inoculated with seed sludge that previously showed thermophilic TA-degrading activity (S. Thierry, I. Ramirez, C. Allouche, H. Ferrer \& H. Macarie, unpublished results). Prior to inoculation, the seed sludge consisted of non-granulated particles smaller than $0.23 \mathrm{~mm}$ ( $>90 \%$ of total suspended solids) and was stored at room temperature without feeding for 316 days. The reactor was fed initially with synthetic PTA wastewater ( $\mathrm{pH} 6 \cdot 7$ ) containing TA $\left(1.32 \mathrm{~g} \mathrm{l}^{-1}\right)$, benzoic acid $\left(0.5 \mathrm{~g} \mathrm{l}^{-1}\right)$, p-toluic acid $\left(0 \cdot 5 \mathrm{~g} \mathrm{l}^{-1}\right)$, trimellitic acid $\left(0 \cdot 24 \mathrm{~g} \mathrm{l}^{-1}\right)$, phthalic acid $\left(0 \cdot 12 \mathrm{~g} \mathrm{l}^{-1}\right)$, acetic acid $\left(0 \cdot 5 \mathrm{~g} \mathrm{l}^{-1}\right), \mathrm{NH}_{4} \mathrm{Cl}\left(0 \cdot 4 \mathrm{~g} \mathrm{l}^{-1}\right), \mathrm{K}_{2} \mathrm{HPO}_{4}\left(0 \cdot 1 \mathrm{~g} \mathrm{l}^{-1}\right)$, $\mathrm{FeSO}_{4} .7 \mathrm{H}_{2} \mathrm{O}\left(0.04 \mathrm{~g} \mathrm{l}^{-1}\right)$, and trace metals (El Mamouni et al., 1995). After 118 days of operation, the synthetic feed was replaced with TA as the sole carbon source at a concentration of $3.41 \mathrm{~g} \mathrm{l}^{-1}$ [theoretical chemical oxygen demand (COD) concentration, $4.93 \mathrm{~g} \mathrm{l}^{-1}$ ] to further enrich the microbial consortia degrading TA. The reactor temperature was controlled at $55^{\circ} \mathrm{C}$ by recirculating heated water through its double-jacket column. Throughout the study, the hydraulic retention time (HRT) and volumetric organic loading rate $(\mathrm{Bv})$ were maintained at 1 day and $5 \mathrm{~kg} C O D \mathrm{~m}^{-3}$ day $^{-1}$, respectively. Complete mixing was provided to prevent the development of substrate gradient or stratified microbial communities in the reactor column. Reactor performance was evaluated by monitoring the removal efficiency of terephthalic, benzoic, $p$-toluic, trimellitic, phthalic and acetic acids as well as total and soluble COD. Biomass samples were collected from the sludge bed at days 103, 172, 200 and 259, and immediately stored in anaerobic serum bottles upon collection. Due to sampling difficulty, the biomass from the packing material was only taken after the shutdown of the reactor on day 272. These sludge samples were used for further microbiological analyses.

Anaerobic batch experiment and chemical analyses. The sludge sample taken from the hybrid reactor at day 200 was anaerobically transferred into $120 \mathrm{ml}$ serum bottles containing $50 \mathrm{ml}$ culture medium [final volatile suspended solid (VSS), $200 \mathrm{mg} \mathrm{l}^{-1}$ ]. The medium $(\mathrm{pH} 7 \cdot 2-7 \cdot 4)$ contained $5 \mathrm{mM}$ TA, inorganic nutrients $\left(\mathrm{mg} \mathrm{l}^{-1}\right)\left(\mathrm{NH}_{4} \mathrm{Cl}, 170 ; \mathrm{CaCl}_{2} \cdot 2 \mathrm{H}_{2} \mathrm{O}, 17 ; \mathrm{MgCl}_{2} .6 \mathrm{H}_{2} \mathrm{O}, 125\right.$; $\mathrm{FeCl}_{3} \cdot 6 \mathrm{H}_{2} \mathrm{O}, 4 \cdot 1 ; \mathrm{KCl}, 90 ; \mathrm{MnCl}_{2} \cdot 4 \mathrm{H}_{2} \mathrm{O}, 1 \cdot 4 ; \mathrm{CoCl}_{2} \cdot 6 \mathrm{H}_{2} \mathrm{O}, 2 \cdot 1$; $\mathrm{H}_{3} \mathrm{BO}_{3}, \quad 0 \cdot 4 ; \quad \mathrm{CuCl}_{2} .2 \mathrm{H}_{2} \mathrm{O}, 0 \cdot 19 ; \quad \mathrm{Na}_{2} \mathrm{MoO}_{4} .2 \mathrm{H}_{2} \mathrm{O}, 0 \cdot 18 ;$ and $\mathrm{ZnCl}_{2}, 0 \cdot 15$ ) and micro nutrients $\left(\mu \mathrm{g} \mathrm{l}^{-1}\right.$ ) (biotin, 4; folic acid, 4; pyridoxine. $\mathrm{HCl}, 20$; riboflavin, 10; thiamine, 10; pantothenic acid, 10; nicotinic acid, 10; vitamin $\mathrm{B}_{12}, 0 \cdot 2$; 4-aminobenzoic acid, 10; and thioctic acid, 10). All cultivations were carried out at $55^{\circ} \mathrm{C}$ and under an atmosphere of $80 \% \mathrm{~N}_{2}-20 \% \mathrm{CO}_{2}$ (v/v) without shaking. During incubation, a $0.5 \mathrm{ml}$ liquid sample was withdrawn every $2-3$ days and filtered immediately through a $0 \cdot 45 \mu \mathrm{m}$ filter prior to chemical analysis.

Soluble volatile fatty acid concentration was determined using a gas chromatograph equipped with a flame-ionization detector (Shimadzu GC-14B), and an HP-FFAP capillary column (Agilent Technologies). The temperatures at the injection port, in the oven and at the detector port were 150,135 and $150{ }^{\circ} \mathrm{C}$, respectively, with nitrogen as the carrier gas. Aromatic compounds were determined by HPLC using a Shimadzu model FCV-10AL instrument equipped with a Shim_Pack VP-ODS separation column and an SPD-M10A UV-detector. The solvent used was $60 \%(\mathrm{v} / \mathrm{v})$ methanol containing

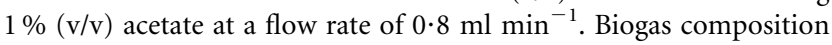
(methane, hydrogen and carbon dioxide) was analysed with a gas chromatograph GC-17A (Shimadzu) equipped with a thermal conductivity detector, and a $2 \mathrm{~m}$ stainless Supelco Porapak Q column (80/100 mesh) with nitrogen as the carrier gas.

Scanning electron microscopy (SEM). The sludge sample taken at day 200 was fixed with $2 \cdot 5 \%$ glutaraldehyde overnight, mounted on poly-L-lysine-coated cover slips, and dehydrated in an ethanol series [25\% (v/v), $5 \mathrm{~min} ; 50 \%, 5 \mathrm{~min} ; 75 \%, 5 \mathrm{~min} ; 95 \%, 10 \mathrm{~min}$; 
$100 \%, 10 \mathrm{~min}$; three times], followed by critical-point drying, then sputter coated with gold. The cells were examined using a Philips XL30 FEG scanning electron microscope.

Terminal-RFLP. Analysis of $16 \mathrm{~S}$ rRNA gene-based terminal-RFLP (T-RFLP) was performed according to a protocol described previously (Liu et al., 1997). From each sample taken from the sludge bed (at days 103, 172, 200 and 259) and the packing materials (at day 272), total community DNA was extracted using a protocol described previously (Liu et al., 1997), and used in the subsequent PCR amplification with a domain Bacteria-specific forward primer 47f (5'-Cy5-CYTAACACATGCAAGTCG- $\left.3^{\prime}\right)$ and a reverse primer 927r (5'-ACCGCTTGTGCGGGCCC-3') (Amann et al., 1995). The amplified PCR products were purified with the QIAquick PCR purification kit (Qiagen), and digested with three different tetrameric restriction nucleases ( $M s p \mathrm{I}, \mathrm{Rsa \textrm {I }}$ and $\mathrm{HhaI}$ ). The digested products were denatured at $95{ }^{\circ} \mathrm{C}$ for $2 \mathrm{~min}$, immediately chilled on ice, and analysed using a model CEQ 8000 automated sequencer (Beckman Coulter) at $55^{\circ} \mathrm{C}$ and $4.8 \mathrm{kV}$ for $2 \mathrm{~h}$. The lengths of fluorescently labelled fragments were determined by comparison with internal standards using CEQ 8000-genetic analysis system software (Beckman Coulter). Only the T-RFs with abundance greater than $1 \%$ of total intensity were used. For individual samples, the T-RFLP fingerprints were obtained based on the mean fingerprinting profiles of three different analyses. The observed T-RF lengths were later compared with and identified from the predicted T-RF lengths of the dominant clones obtained in the bacterial clone library.

Construction of 16S rRNA gene clone libraries. Community $16 \mathrm{~S}$ rRNA genes from domain Bacteria and Archaea were PCRamplified with bacterial primer set EUB008F (Hicks et al., 1992) and 1512R (Kane et al., 1993) and archaeal primer set A1F/A1100R (Embley et al., 1992), respectively. Total community DNA extracted from the samples taken at days 200 and 259 was used as the template in PCR-reaction mixtures, which contained $1 \times$ PCR buffer (Invitrogen), $200 \mu \mathrm{M}$ dNTPs, $2 \mathrm{mM} \mathrm{MgCl}_{2}, 0 \cdot 2 \mu \mathrm{M}$ of each primer, and $2.5 \mathrm{U}$ Taq DNA polymerase (Invitrogen) in a final volume of $100 \mu \mathrm{l}$. DNA amplification was performed in a Hybaid PCR Express thermocycler using a thermal program consisting of a hotstart at $94^{\circ} \mathrm{C}$ for $1 \mathrm{~min}, 30$ cycles of denaturation $\left(30 \mathrm{~s}\right.$ at $\left.94^{\circ} \mathrm{C}\right)$, annealing $\left(30 \mathrm{~s}\right.$ at $\left.55^{\circ} \mathrm{C}\right)$ and extension $\left(30 \mathrm{~s}\right.$ at $\left.72{ }^{\circ} \mathrm{C}\right)$, and a final extension at $72{ }^{\circ} \mathrm{C}$ for $5 \mathrm{~min}$. PCR products after confirmation were used in the construction of the 16S rRNA gene clone libraries as reported previously (Liu et al., 2002).
Phylogenetic analysis and probe design. Nearly full-length $16 \mathrm{~S}$ rRNA gene sequences of representative clones were compared to available rRNA gene sequences in GenBank using the NCBI BLAST program (Altschul et al., 1997) and checked for chimeric artifacts using the CHECK-CHIMERA tool available in the Ribosomal Database Project (RDP) (Maidak et al., 2000). Sequences of those selected clones and closely related bacterial species were aligned using the CLUSTAL_W program available in the BioEdit software package (Hall, 1999). A neighbour-joining tree with the Jukes-Cantor method was constructed with bootstrapping (1000 replicates) using the MEGA2 program (Kumar et al., 2001). For probe design, sequences closely related to the clone sequences were retrieved and imported into a sequence alignment program, ARB (Ludwig et al., 2004). After sequence alignment, $16 \mathrm{~S}$ rRNA-targeted oligonucleotide probes targeting specific groups of sequences were designed using the probe design function provided in ARB.

Fluorescence in situ hybridization analysis. The TA-degrading sludge samples taken were gently washed three times with $0 \cdot 1 \mathrm{M}$ PBS and fixed with $4 \%$ paraformaldehyde at $4{ }^{\circ} \mathrm{C}$ overnight. Fluorescence in situ hybridization (FISH) was conducted according to a protocol previously described (Amann, 1995). In brief, hybridization was carried out at $46^{\circ} \mathrm{C}$ for $3 \mathrm{~h}$ with hybridization buffer $(0.9 \mathrm{M} \mathrm{NaCl}, 20 \mathrm{mM}$ Tris/ $\mathrm{HCl} \mathrm{pH} 7 \cdot 2,0.01 \%$ SDS $)$ containing $5 \mathrm{ng} \mathrm{ll}^{-1}$ of each fluorescent probe. When necessary, samples were briefly vortexed for $3 \mathrm{~min}$ before being immobilized on glass slides, and then were subjected to a freeze-and-thaw protocol (Sekiguchi et al., 1999) to improve probe hybridization efficiency. Sludge samples were initially hybridized with the probe NON338 labelled with Cy3 to exclude nonspecific-probe-binding (Wallner et al., 1993), and then were analysed with the domain- and group-specific oligonucleotide probes listed in Table 1 to provide microbial community structure. The hybridization efficiencies of the domain probes were verified by staining with 4',6-diamidino-2-phenylindole (DAPI). For the optimization of newly designed probes, the optimal formamide concentration was determined by simultaneously comparing the hybridization signal of microbial cells in sludge samples under different formamide concentrations $(0-35 \%)$ in the hybridization buffer. An Olympus BX51 epifluorescence microscope equipped with a cooled CCD camera SPOT-RT Slider (Diagnostic Instruments), a $100 \mathrm{~W}$ HBO bulb and fluorescence filter sets (U-MWU2, U-MWB2 and U-MF2) was used for the FISH analysis. The image analysis software, MetaMorph (Universal Imagine Corporation), was used to control the camera and to perform image analysis. Semi-quantitative FISH analysis was performed by analysing at least

Table 1. Oligonucleotide probes used in this study

\begin{tabular}{|c|c|c|c|c|}
\hline Probe name & Target & Probe sequence $\left(5^{\prime}-3^{\prime}\right)^{*}$ & FA $(\%) \dagger$ & Reference \\
\hline ARC915 & Archaea & GTGCTCCCCCGCCAATTCCT & 35 & Stahl \& Amann (1991) \\
\hline MG1200 & Methanomicrobiales & CGGATAATTCGGGGCATGCTG & 10 & Raskin et al. (1994) \\
\hline MB1174 & Methanobacteriaceae & TACCGTCGTCCACTCCTTCCTC & 35 & Raskin et al. (1994) \\
\hline CF319a & Cytophaga-Flexibacter group & TGGTCCGTGTCTCAGTAC & 35 & Manz et al. (1996) \\
\hline delta402 & $\delta$-Proteobacteria & CGGCGTCGCTGCGTCAGG & 30 & Amann et al. (1995) \\
\hline delta-TA1 & $\delta$-Proteobacteria TA group & TCCAAGYTCCCCTTACGG & 20 & Wu et al. (2001) \\
\hline GNSB663 & Clones in green non-sulfur bacteria & TAGCCCGCCAGTCTTGAACG & 20 & Sekiguchi et al. (1999) \\
\hline TA55_OP5 & OP5-like cluster in this study & CGCCCATTGCCCAAATTT & 25 & This study \\
\hline
\end{tabular}

${ }^{*} \mathrm{Y}$ indicates $\mathrm{T}$ or $\mathrm{C}$.

$\dagger \mathrm{FA}$, formamide concentration used in hybridization buffer. 
12 microscopic fields selected randomly from the hybridization of individual probes (Bouchez et al., 2000; Schmid et al., 2000). Cells hybridized to a given probe in each field were expressed as a percentage of the total area of archaeal or bacterial domain probes hybridized by the ARC915 or EUB338_I/II/III, respectively, using the functions provided in MetaMorph.

\section{RESULTS AND DISCUSSION}

\section{Reactor performance}

Table 2 summarizes the performance of the laboratoryscale hybrid reactor during the study period. The reactor showed effective degradation activities during the initial biomass reactivation period. Between days 73 and 118 the total COD removal efficiency was greater than $75 \%$ and the removal efficiencies of specific compounds, except $p$-toluic acid, were higher than $94 \%$. The in situ apparent specific TA-degrading capacity observed, $0.7 \mathrm{~g}(\mathrm{~g} \mathrm{VSS})^{-1}$ day $^{-1}$, was higher than the highest values of $0.47 \mathrm{~g}$ TA $\left(\mathrm{g} \mathrm{VSS}^{-1}\right.$ day $^{-1}$ reported for mesophilic TA-degrading anaerobic reactors (Kleerebezem et al., 1999c).

The high COD removal efficiency was believed to be mainly attributable to biological activity through successful enrichment of the TA-degrading consortia. It is known that TA has a high solubility $\left(\sim 140 \mathrm{~g} \mathrm{l}^{-1}\right.$ at $\left.\mathrm{pH}>5 \cdot 5\right)$ (Macarie et al., 1992), and it was reported that TA could not be accumulated or adsorbed within the sludge in the hybrid reactor under the applied loading (Kleerebezem et al., 1997). Furthermore, TA does not contain hydrophobic groups like methyl, which would favour partitioning toward lipidic membranes of sludge biomass. Thus, the possibility of physical adsorption suspected earlier (Macarie et al., 1992; Cheng et al., 1997) was rejected.

At day 119, the feed was changed from synthetic PTA wastewater to feed with TA as the sole carbon source. Between days 126 and 172 the total and soluble COD removal efficiencies further improved to approximately 92.6 and $97 \cdot 8 \%$, respectively. This improvement was attributed to the absence of the refractory $p$-toluic acid. TA removal was over $99 \%$, and the in situ apparent specific TA-degrading capacity further increased from 0.7 to $1.6 \mathrm{~g}$ $\left(\mathrm{g} \mathrm{VSS}^{-1}\right.$ day $^{-1}$. In addition, no metabolic intermediates of TA degradation were detected.

However, between days 173 and 200, the total COD- and TA-removal efficiency decreased from 90 and $98 \%$ to 55 and $89 \%$, respectively. Intermediates including acetate, propionate and butyrate were found at concentrations of approximately $4,2 \cdot 8$ and $6 \mathrm{mM}$, respectively, and represented approximately $21 \%$ of the carbon coming from the degraded TA. The increases in these intermediates were suspected to be related to organic overload due to low biomass inventory in the reactor, since all other operating conditions ( $\mathrm{Bv}, \mathrm{HRT}$, temperature, $\mathrm{pH}$, etc.) remained unchanged. However, the decrease in biomass inventory was observed not to be related to sludge washout, and the reactor performances recovered on day 208. Thus, the exact cause of the decrease in removal efficiency remained unclear.

Table 2. Performances of the thermophilic reactor and specific degrading activity of its sludge

\begin{tabular}{|c|c|c|c|c|c|}
\hline & \multicolumn{5}{|c|}{ Time period } \\
\hline & Day 0-118 & Day 119-172 & Day 173-200 & Day $201-217$ & Day 234-258 \\
\hline \multicolumn{6}{|l|}{ Reactor operating conditions } \\
\hline \multirow[t]{3}{*}{$\operatorname{Bv}\left(\mathrm{kg} \mathrm{COD} \mathrm{m}^{-3}\right.$ day $\left.^{-1}\right)$} & $5 \cdot 2(0 \cdot 3)$ & $4 \cdot 9(0 \cdot 4)$ & $5 \cdot 4(0 \cdot 2)$ & $5 \cdot 4(0 \cdot 1)$ & $5 \cdot 4(0 \cdot 1)$ \\
\hline & \multicolumn{5}{|c|}{ Time period } \\
\hline & Day 73-118 & Day $126-172$ & Day $173-200$ & Day 208-217 & Day $241-258$ \\
\hline \multicolumn{6}{|l|}{ Reactor performance } \\
\hline Total COD removal efficiency (\%) & $75 \cdot 4(5 \cdot 7)$ & $92 \cdot 6(5 \cdot 5)$ & $90 \cdot 0$ to $55 \cdot 0(\mathrm{NA})$ & $92 \cdot 9(2 \cdot 9)$ & $75 \cdot 8(6 \cdot 3)$ \\
\hline Soluble COD removal efficiency (\%) & $80 \cdot 4(4 \cdot 1)$ & $97 \cdot 8(1 \cdot 8)$ & $92 \cdot 0$ to $60 \cdot 0(\mathrm{NA})$ & $96 \cdot 7(2 \cdot 6)$ & $90 \cdot 2(2 \cdot 3)$ \\
\hline \multicolumn{6}{|l|}{ Removal efficiency of specific compounds (\%) } \\
\hline TA & $98 \cdot 0(5 \cdot 6)$ & $99 \cdot 3(1 \cdot 2)$ & $98 \cdot 0$ to $88 \cdot 8(\mathrm{NA})$ & $97 \cdot 7(1 \cdot 9)$ & $95 \cdot 7(4 \cdot 8)$ \\
\hline Benzoic acid & $98 \cdot 6(3 \cdot 1)$ & NA & NA & NA & NA \\
\hline$p$-Toluic acid & $37 \cdot 5(19 \cdot 0)$ & NA & NA & NA & NA \\
\hline Trimellitic acid & $95 \cdot 6(8 \cdot 6)$ & NA & NA & NA & NA \\
\hline Phthalic acid & $94 \cdot 4(16 \cdot 4)$ & NA & NA & NA & NA \\
\hline Acetic acid & $98 \cdot 6(5 \cdot 6)$ & NA & NA & NA & NA \\
\hline \multicolumn{6}{|l|}{ Sludge in situ apparent degrading activity } \\
\hline For soluble COD [g COD removed (g VSS) ${ }^{-1}$ day $^{-1}$ ] & $2 \cdot 9(0 \cdot 3)$ & $2 \cdot 8(0 \cdot 2)$ & $2 \cdot 8$ to $1 \cdot 7(\mathrm{NA})$ & $2 \cdot 4(0 \cdot 04)$ & $2 \cdot 4(0 \cdot 1)$ \\
\hline For TA [g TA removed $\left(\mathrm{g} \mathrm{VSS}^{-1} \mathrm{day}^{-1}\right]$ & $0 \cdot 7(0 \cdot 1)$ & $1 \cdot 6(0 \cdot 2)$ & $1 \cdot 8$ to $1 \cdot 2(\mathrm{NA})$ & $1 \cdot 4(0 \cdot 01)$ & $1 \cdot 2(0 \cdot 1)$ \\
\hline
\end{tabular}

Values in parentheses represent standard deviations of the measured values. Bv, volumetric organic loading rate; NA, not applicable. 
Between days 218 and 219 failure of the temperature controller occurred, which resulted in an increase in operational temperature to $92^{\circ} \mathrm{C}$ for a period of approximately $3 \mathrm{~h}$. Another perturbation in the system was encountered between days 225 to 232, when the feed and recycling pump failed, and the reactor operation had to be stopped. However, the reactor showed extremely high resistance to such drastic perturbations, and its performance recovered 1 week after operating conditions were restored. Good removal efficiencies were obtained again from day 241 onwards; $75 \cdot 8 \%$ for total COD and $95 \cdot 7 \%$ for TA.

TA degradation was further studied using a batch experiment with a sludge sample taken at day 200. No fermentative intermediates were detected during the incubation, except for trace levels of benzoate $(\sim 7-9 \mu \mathrm{M})$ observed in the first 4 days. Complete TA degradation with concurrent formation of methane was achieved after 21 days of incubation. The rate of methane production $[3.82 \mathrm{mmol}$ $\left(\mathrm{g} \mathrm{VSS}^{-1}\right.$ day $^{-1}$ ] was three times higher than that of TA degradation $\left[1.35 \mathrm{mmol}\right.$ TA $(\mathrm{g} \text { VSS})^{-1}$ day $^{-1}$ or $0.224 \mathrm{~g}$ $\mathrm{TA}\left(\mathrm{g} \mathrm{VSS}^{-1} \mathrm{day}^{-1}\right]$. The TA-degrading activity obtained under the batch conditions was much lower than the sludge specific removal capacity observed during reactor operation (Table 2). This decrease was possibly due to the absence of agitation to enhance mass transfer and the use of a low TA concentration $(5 \mathrm{mM})$ in the batch test. Overall performance results suggest that the thermophilic reactor could be equally or more effective in degrading TA than the mesophilic reactor, and would be an attractive biological process for future treatment of PTA wastewater.

\section{SEM-based morphological observations}

SEM analysis revealed at least six different dominant morphotypes present in the sludge sample taken at day 200; each morphotype is indicated by an arrow in Fig. 1 . These included bamboo-shaped cells $(0 \cdot 6-0 \cdot 7 \times 3 \cdot 3-15 \mu \mathrm{m})$ (arrow 1), rods with flat ends $(0 \cdot 6-0 \cdot 7 \times 1 \cdot 6-3 \cdot 3 \mu \mathrm{m})$ (arrow 2), fat rods $(0 \cdot 6-0 \cdot 8 \times 1 \cdot 5 \mu \mathrm{m}$ ) (arrow 3 ), very small rods $(0 \cdot 3 \times 1 \cdot 6-2 \cdot 0 \mu \mathrm{m})$ (arrow 4$)$, long and slender rods $(0 \cdot 3 \times 3 \cdot 3-4 \cdot 8 \mu \mathrm{m})$ (arrow 5), and thin filaments $(0 \cdot 2 \times$ 25-33 $\mu \mathrm{m}$ ) (arrow 6). The fat rods (arrow 3) were the dominant cells found in the thermophilic TA-degrading hybrid reactor, and are presumed to be responsible for TA degradation. The second most dominant cells were bamboo-shaped cells (arrow 1) and rods with flat ends (arrow 2), which closely resembled Methanosaeta-like species, which are methanogens that utilize acetate.

\section{Effect of operational conditions on microbial population dynamics as revealed by 165 rRNA gene-based T-RFLP}

Fig. 2 shows the T-RFLP profiles for samples D103 (day 103), D172 (day 172), D200 (day 200) and D259 (day 259) taken from the sludge bed, and sample D272 (day 272) taken from the surface of the packing material. These T-RFLP profiles were correlated to reactor operation and

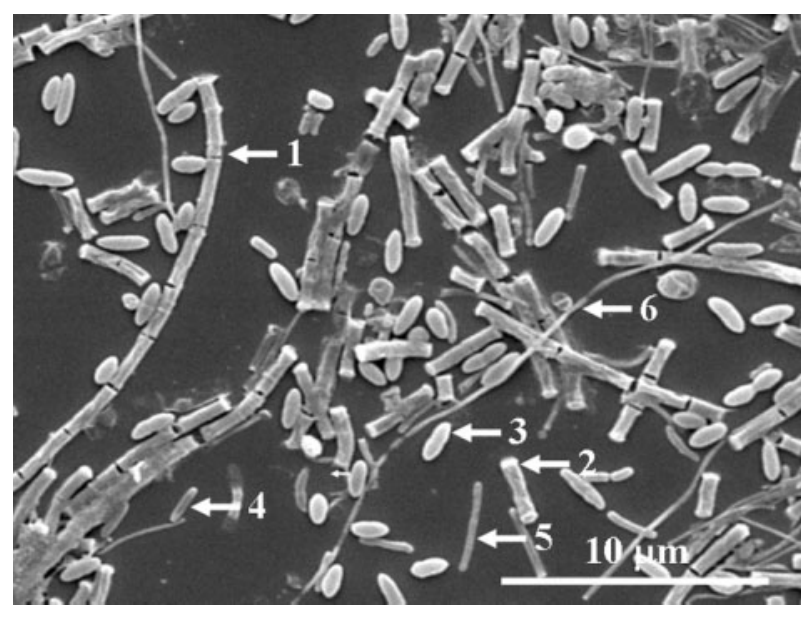

Fig. 1. Scanning electron micrograph of dominant microorganisms observed in thermophilic TA-degrading anaerobic sludge sample taken at day 200. Arrows indicate the six dominant bacterial morphotypes (see text for details).

performance. Among samples D103, D172 and D200 (Fig. 2a-c) a similar MspI-digested T-RFLP profile was observed which had a $171 \mathrm{bp}$ peak as the major T-RF ( $\sim 42-52 \%$ of total fragment intensity) in addition to 14-15 other detectable, but minor, T-RFs. The change of substrate composition at day 119 did not cause an apparent shift in the microbial population profiles from sample D103 to sample D200. This observation suggested that the microbial populations represented by the $171 \mathrm{bp}$ T-RF could play an important role in TA degradation in the reactor. Similar results were observed in the T-RFLP profiles with RsaI and HhaI digestion (data not shown).

In contrast, a significant shift in the MspI-digested T-RFLP profiles was observed from sample D200 (Fig. 2c) to sample D259 (Fig. 2d). This change in the bacterial population profile was attributed to the thermal shock and pump failure that occurred in this period. While the abundance of the $171 \mathrm{bp}$ T-RF significantly decreased from $42-52$ to $8 \%, 22$ other detectable T-RFs with abundances ranging from 1.03 to $12.11 \%$ were observed. Since both soluble COD removal and TA degradation efficiency ( $>90$ and $96 \%$, respectively) had already recovered at day 258 , the appearance of these new T-RFs suggested that they too were responsible for TA degradation. Perhaps they could have been out-competed or suppressed as the minor populations by the microbial populations represented by the $171 \mathrm{bp}$ T-RF under steady-state operation between days 103 and 218.

The MspI-digested T-RFLP profile was further determined for the biofilm sample D272 (i.e. attached growth) obtained from the surface of reactor packing materials. The profile (Fig. 2e), showing $171 \mathrm{bp} \mathrm{T-RF} \mathrm{as} \mathrm{the} \mathrm{only} \mathrm{major} \mathrm{peak}$ ( $\sim 72 \%$ of total peak area), was very similar to samples D103, D172 and D200 obtained from the sludge bed (i.e. 


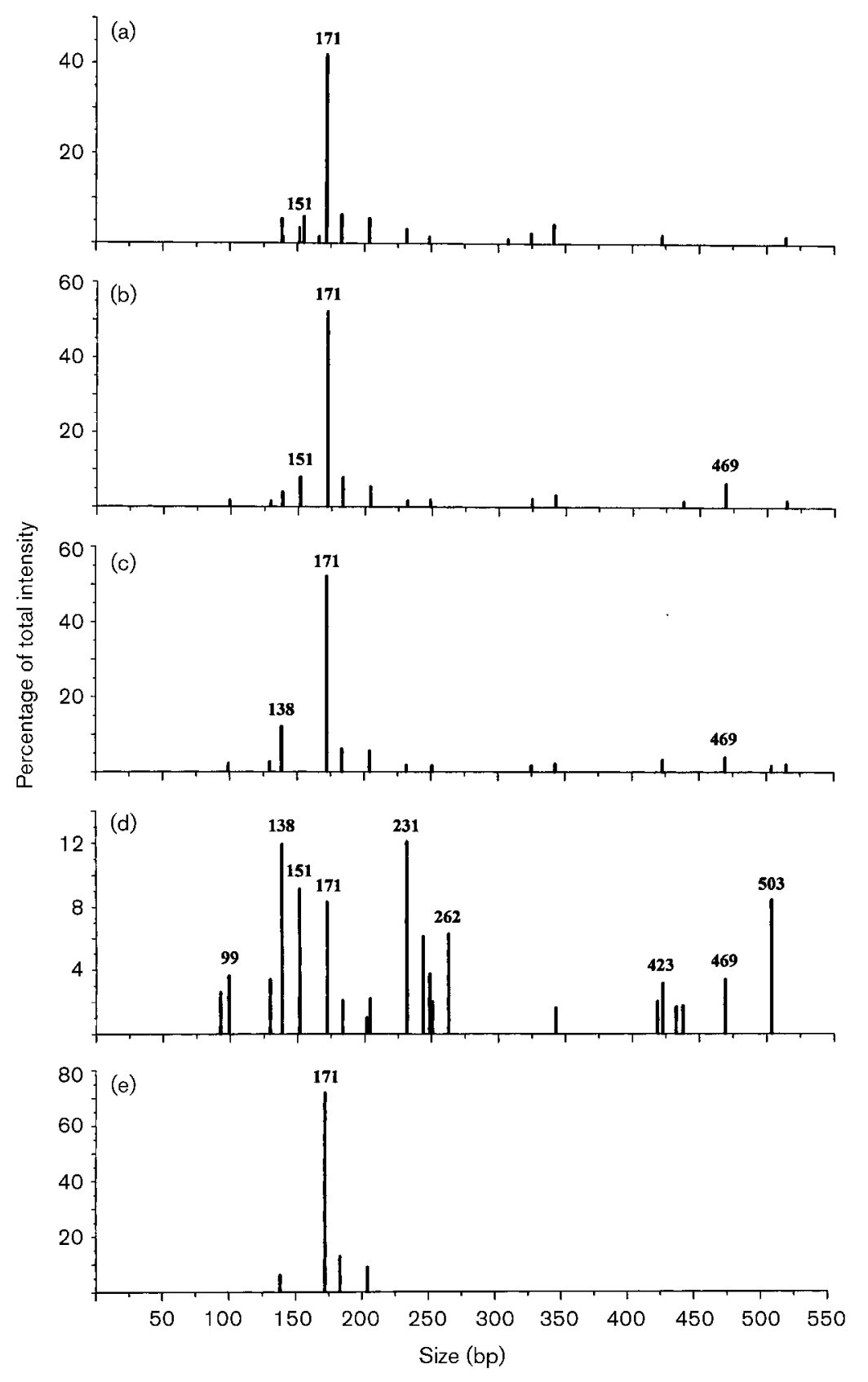

Fig. 2. Electropherograms of $M s p l$-digested T-RFLP fingerprints obtained from the thermophilic TA-degrading sludge bed samples at days 103 (a), 172 (b), 200 (c) and 259 (d) and packing materials at day 272 (e). suspended growth). Apparently, the difference in attached growth and suspended growth did not have a significant effect on the TA-degrading community structure when good mixing was provided in the reactor under a steadystate operation. However, when perturbation (e.g. heat shock and pump failure) occurred, the microbial population structure in the sludge bed, as observed in Fig. 2(d), could be more susceptible to environmental changes than that on the surface of the packing materials. This was attributed to the physical protection provided to the microbial populations by the formation of a biofilm (Stickler, 1999). A similar observation was reported in reactors with immobilized biomass under temperature perturbation (van Lier, 1996).
It was possible that the attached growth could have served as a good seeding source to help the reactor recover rapidly from process upsets, for example, between day 219 and day 258 in this study. The amount of biomass attached on the surface of the packing materials was not determined in this study due to technical difficulty in sampling during reactor operation, but was reported to be $22 \cdot 28 \%$ of the total sludge biomass from our previous study (S. Thierry, I. Ramirez, C. Allouche, H. Ferrer \& H. Macarie, unpublished results). In view of this, reseeding mechanisms could possibly provide full-scale hybrid reactors with better operational stability than systems with suspended sludge biomass. This explanation would be more convincing if the microbial community structures on the surface of the 
packing material could have been constantly monitored during the reactor operation.

\section{Thermophilic TA-degrading consortium as revealed by 16S rRNA gene clone libraries}

To further understand the thermophilic TA-degrading consortia, the phylogenetic composition of the fermentative bacteria and methanogens in the reactor was examined through clone library construction. An archaeal clone library was constructed for the methanogenic counterpart in sample D200. In total, 60 clones were selected and classified into five different sequence types or phylotypes after clone screening and sequencing. Phylogenetic analysis (Fig. 3) showed that four (TTA_A1, 4, 5 and 64; $93 \%$ of total archaeal clones) of those five phylotypes were closely related to Methanothrix thermophila in the acetoclastic Methanosaeta group. The remaining clone (TTA_A24; $7 \%$ ) was related to hydrogen-utilizing Methanospirillum species and an environmental clone UASB_TA02 from a mesophilic TA-degrading UASB process (Wu et al., 2001).

For the fermentative syntrophs from the Bacteria domain, two clone libraries were constructed for sludge samples D200 and D259 to provide better insights into the bacterial community structure before and after perturbation. In total, 147 bacterial clones from sample D200 and 114 bacterial clones from sample D259 were selected, screened, fully sequenced, and classified into 27 and 23 different phylotypes, respectively. Among them, five and three phylotypes from samples D200 and D259, respectively, were further confirmed as chimeric products and excluded from the phylogenetic analysis.

The phylogenetic tree in Fig. 4 indicated that the 22 phylotypes obtained from sample D200 were affiliated with nine different bacterial divisions. Most phylotypes were from the Gram-positive low-G $+\mathrm{C}$ group (LGC) (7 phylotypes, $42 \cdot 2 \%$ of total bacterial clones) and the candidate division OP5 (5 phylotypes, $30 \cdot 8 \%$ ). In the LGC, the most dominant phylotype (TTA_B12; 31.9\%) and phylotype TTA_B5 $(0 \cdot 7 \%)$ were affiliated with the Desulfotomaculum group, which consists of physiologically diverse isolates and environmental clone sequences from various thermophilic and mesophilic environments (Castro et al., 2000; Dojka et al., 1998; Imachi et al., 2002; Stubner \& Meuser, 2000). The second most dominant phylotype (TTA_B6; 6·1\%) was closely related to environmental clone MUG10, derived from a mesophilic UASB granule (Sekiguchi et al., 1998). The remaining phylotypes at low abundance were clustered together with an uncultured hot spring clone OPB54 (Hugenholtz et al., 1998) and environmental clone SHA118 , derived from an anaerobic dechlorinating bioreactor (Schlötelburg, 2001). The five phylotypes in the candidate division OP5 formed a cluster closely related to environmental clones obtained from an anaerobic dechlorinating bioreactor (Schlötelburg, 2001) and a contaminated aquifer (Dojka et al., 1998). The remaining ten phylotypes from sample D200 were found in the Cytophaga-FlexibacterBacteroides (CFB) group (2 phylotypes, $7 \cdot 5 \%$ of total clones), the $\delta$-Proteobacteria (3 phylotypes, $4.9 \%$ ), the $\beta$ Proteobacteria (1 phylotype, $0.7 \%$ ), Chlorobi (1 phylotype, $1 \cdot 4 \%$ ), the candidate division OP8 (1 phylotype, $4 \cdot 8 \%$ ), Planctomycetes (1 phylotype, $0 \cdot 7 \%)$, and Thermotogae (1 phylotype, $0 \cdot 7 \%)$.

In sample D259, the 20 phylotypes were distributed in six different bacterial divisions (Fig. 4). Due to the effect of system perturbation, 14 out of these 20 phylotypes were not affiliated with any phylotype from sample D200. Six of these 14 phylotypes were from the LGC division, of which two (TTA_H16 and 39; 6•1\%) were closely related to clone ST12 (derived from a thermophilic anaerobic enrichment culture that reduces tetrachloroethene to cis1,2-dichloroethene; Kengen et al., 1999), and the remaining four $(15 \cdot 8 \%)$ were closely related to Thermanaerovibrio acidaminovorans and environmental clone MUG10 (obtained from a mesophilic UASB granule; Sekiguchi et al., 1998). Four more phylotypes $(21 \cdot 1 \%)$ were found in the CFB group, forming a cluster closely related to environmental clones (clones IA-5 and IIIB-1) derived from dechlorinating consortia and Flexibacter echinicida. The final four phylotypes were related to the $\beta$-Proteobacteria,

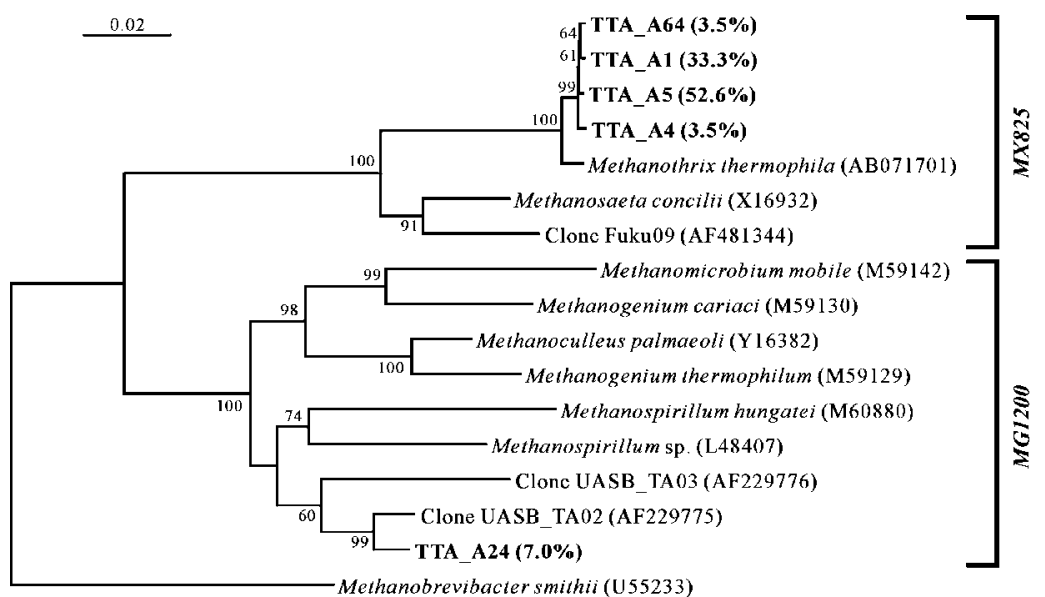

Fig. 3. Phylogenetic affiliations of the $16 \mathrm{~S}$ rRNA gene sequences retrieved from the cloning analyses of domain Archaea. The phylogenetic tree was constructed using the neighbour-joining algorithm with JukesCantor parameter (bootstrapping number, 1000). The $16 \mathrm{~S}$ rRNA gene sequence of Methanobrevibacter smithii (U55233) was selected as the outgroup. Bootstrap values greater than $50 \%$ of the replicates are shown at nodes. The abundance of individual clones is indicated at the end of individual sequences in parentheses. Scale bar, 1 substitution per 50 nucleotides. 


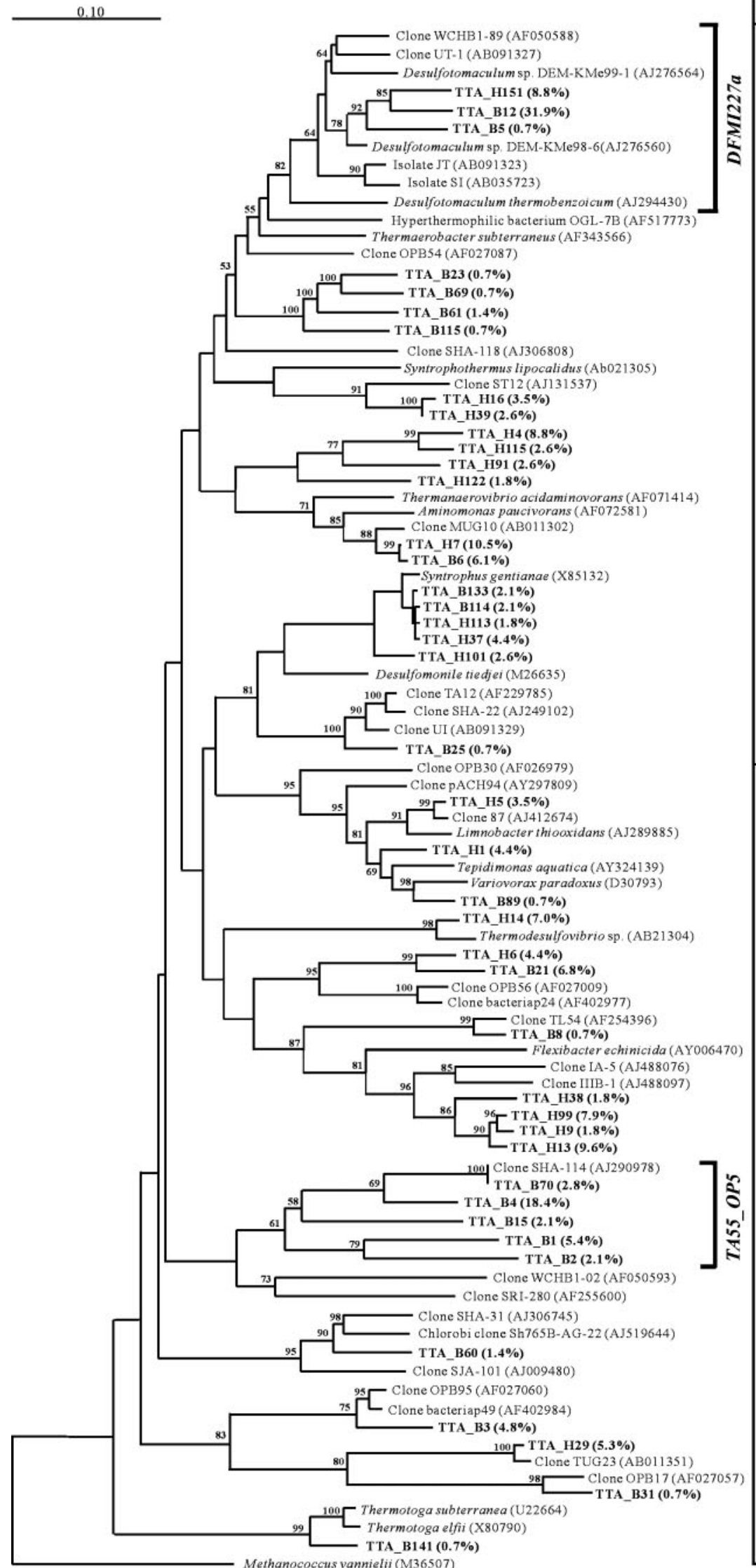

MspI digested T-RF (bp)

\begin{tabular}{|l|l|}
\hline Day 200 & Day 259 \\
\hline
\end{tabular}

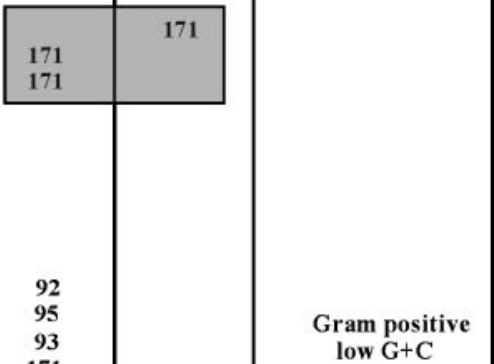

low $\mathrm{G}+\mathrm{C}$

171

99

99
231

231

110

138

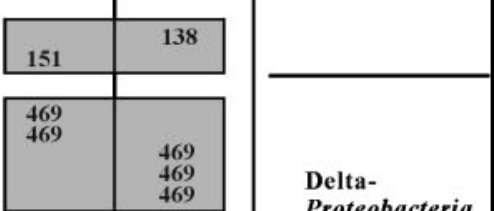

Proteobacteria

121

99

423

Beta-

Proteobacteria

446

\begin{tabular}{|c|c|}
\hline 423 & 423 \\
\hline & \\
& \\
& \\
& \\
& \\
& 503 \\
& 503 \\
& 503 \\
& 503 \\
&
\end{tabular}

423

Nitrospira

527

138

138

138

527

418

03

(1)

342

646

252
Chlorobi

OP 8

OP 5

CFB

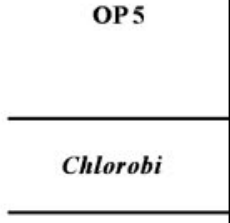

Planctomycetes

Thermotogae 
the thermophilic environmental clone (clone TUG23) (Sekiguchi et al., 1998) in Planctomycetes and Thermodesulfovibrio sp. in Nitrospira.

The clone library results suggested that various microbial populations were capable of degrading TA to acetate, $\mathrm{CO}_{2}$ and hydrogen, which were further mineralized by the methanogenic counterpart. The Desulfotomaculum- and OP5-related phylotypes were the main populations in the hybrid reactor under steady-state operation. However, when perturbations occurred, other phylotypes, for example from the LGC, the CFB, the $\delta$-Proteobacteria and the $\beta$ Proteobacteria, could emerge rapidly and become involved in TA degradation.

It was further observed that in anaerobic TA-degrading reactors, the dominant populations in the thermophilic hybrid reactor were different from those obtained from mesophilic reactors, where a yet-to-be-cultured group from the $\delta$-Proteobacteria was identified as the dominant group (Wu et al., 2001; Qiu et al., 2004). Similar observations were reported between mesophilic and thermophilic methanogenic granular reactors degrading a mixture of sucrose, propionate and acetate (Sekiguchi et al., 1998). Recently, a mesophilic TA-degrading bacterium strain JT within the Desulfotomaculum group was successfully isolated from a UASB granular sludge (Qiu et al., 2004). This further suggested that the Desulfotomaculum group could possibly contain both mesophilic and thermophilic TAdegrading members.

\section{Phylogenetic identity of T-RFs observed in community T-RFLP profiles}

The MspI-digested T-RF sizes of the phylotypes obtained from samples D200 and D259 were initially determined and verified by comparing them with the predicted T-RF sizes from the sequences obtained. The observed T-RF sizes of these phylotypes (Fig. 4) were compared with those observed in the T-RFLP profiles (Fig. 2). This comparison revealed that the most dominant $171 \mathrm{bp} T-\mathrm{RF}$ observed in most of the T-RFLP profiles represented phylotypes related to the Desulfotomaculum group (e.g. TTA_B12). Those T-RFs with sizes of 99, 231 and $262 \mathrm{bp}$ probably represented phylotypes TTA_H16, TTA_H4 and TTA_H122, respectively, in the LGC group. The $469 \mathrm{bp}$ T-RF represented Syntrophus gentianae from the $\delta$ Proteobacteria (e.g. TTA_B114). The T-RFs with sizes of 423 and 503 bp represented phylotypes TTA_H6 and TTA_H13 from the CFB group, respectively. It was further observed that some T-RFs (e.g. $138 \mathrm{bp}$ T-RF and $151 \mathrm{bp}$ T-RF) could represent more than one phylotype, sometimes from different bacterial divisions. For example, the $138 \mathrm{bp}$ T-RF observed in samples could represent phylotypes either from the OP5 (e.g. TTA_B4) or related to $T$. acidaminovorans from the LGC group or possibly both. These results were in synergy with T-RFLP and clone library results.

\section{Thermophilic TA-degrading syntrophic consortium as revealed by FISH}

FISH with rRNA-targeted probes specifically for domains Archaea (ARC915) and Bacteria (EUB338_I/II/III) was used to examine the distribution of bacterial and archaeal cells in the sludge bed taken at day 200. Fig. 5(a) indicates that bacterial cells (green) and archaeal cells (red) accounted for $48 \cdot 1 \pm 3 \cdot 0$ and $49 \cdot 2 \pm 2 \cdot 6 \%$ of the DAPI-stained cells, respectively.

The archaeal population was further investigated using specific probes MX825, MG1200 and MB1174 targeting Methanosaeta, Methanomicrobiales and Methanobacteriaceae, respectively. Cells shaped like bamboo or rods with flat ends hybridized with the probe MX825 specific for the Methanosaeta (red in Fig. 5b), and represented at least $94 \cdot 9 \pm 5 \cdot 2 \%$ of total Archaea cells. No cells were detected by probe MG1200 targeting Methanomicrobiales, even though one phylotype related to Methanospirillum species was obtained. Possibly the Methanospirillum-related archaeal population could not be detected due to the specificity of probe MG1200 to the novel sequence, although this could not be confirmed due to the lack of sequence information for the phylotypes in the probe target region. Alternatively it may not have been detected because of the inability of the FISH technique to detect microbial populations at a low cell number or with a low rRNA content. In contrast, probe MB1174 hybridized to very small rods $(5 \pm 2 \cdot 2 \%$ of archaeal cells), even though the archaeal clone library did not reveal any sequence from the family Methanobacteriaceae (data not shown). These differences between FISH and clone library results could be due to the bias in cell lysis during DNA extraction or primer specificity in PCR amplification.

The $171 \mathrm{bp}$ T-RF phylotypes related to the Desulfotomaculum group were further confirmed using FISH with probe DFMI227a targeting members of the Desulfotomaculum group (Loy et al., 2002). Fig. 5(b) shows that probe DFMI227a could hybridize to fat rods (green), representing

Fig. 4. Phylogenetic affiliations of the $16 \mathrm{~S}$ rRNA gene sequences retrieved from the cloning analyses of domain Bacteria. Calculations were based on the neighbour-joining algorithm (bootstrapping number, 1000). The tree was rooted with the $16 \mathrm{~S}$ rRNA gene sequence of Methanococcus vannielii (M36507). Bootstrap values greater than $50 \%$ of the replicates are shown at nodes. The abundance of individual clones is indicated at the end of individual sequences in parentheses. Scale bar, 1 substitution per 10 nucleotides. In addition, the corresponding Mspl-digested T-RF sizes for those bacterial clones are shown. Those T-RFs common to both of the clone libraries (from sludge samples D200 and D259) are highlighted with grey background. 

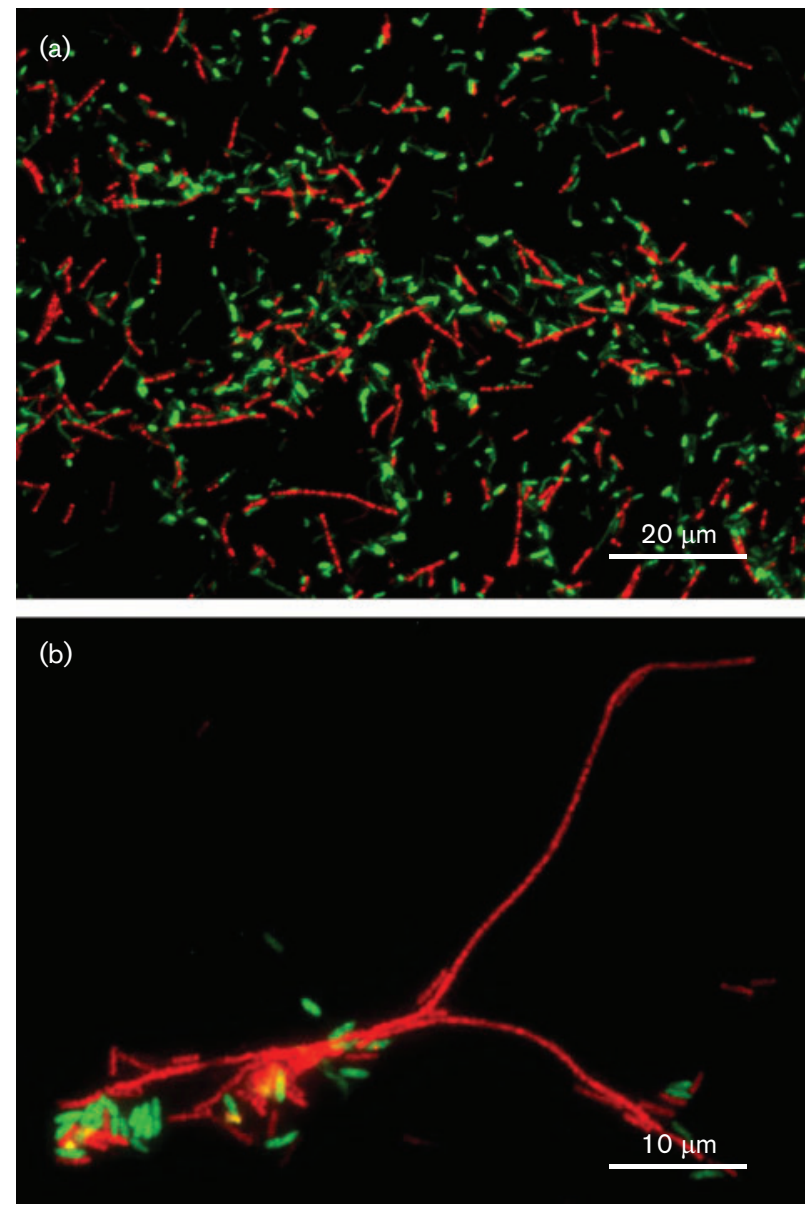

Fig. 5. FISH of thermophilic TA-degrading anaerobic sludge. Microbial distribution was revealed by simultaneous hybridization with domain- and group-specific probes labelled with Сy3 (green) and Cy5 (red). (a) Hybridization with bacterial domain probe (EUB338_I/II/III; green) and archaeal domain probe (ARC915; red). (b) Hybridization with MX825 probe (red) specific for Methanosaeta and DFMI227a probe (green) specific for Desulfotomaculum. Scale bars, $20 \mu \mathrm{m}$ (a), $10 \mu \mathrm{m}$ (b).

approximately $37 \cdot 0 \pm 6 \cdot 6 \%$ of total bacterial cells hybridized by probe EUB338_I/II/III. Thus, these fat rods were probably responsible for the thermophilic TA degradation. Furthermore, a new probe TA55_OP5 was designed and optimized for those phylotypes found in the OP5-like division. It hybridized to very small rod-shape cells, accounting for the second largest fraction of the bacterial populations in the sludge $(26 \cdot 9 \pm 5 \cdot 8 \%)$ (data not shown).

FISH results further indicated that members of the CFB group and $\delta$-Proteobacteria accounted for only $7 \cdot 7 \pm 3 \cdot 2$ and $3 \cdot 2 \pm 0 \cdot 6 \%$, respectively, of total bacterial cells in the methanogenic consortium in sample D200, and exhibited morphological traits of either long slender rods or fat rods (data not shown). In addition, a specific probe delta-TA1 targeting the $\delta$-proteobacterial TA group found in mesophilic TA-degrading sludge (Wu et al., 2001) was used in the FISH analysis, but did not hybridize to any cells. This study further suggested that the thin filaments observed under SEM (arrow 6 in Fig. 1) were members of green non-sulfur bacteria found in thermophilic UASB sludge treating a mixture of sucrose, acetate and propionate (Sekiguchi et al., 1999). However, this possibility was rejected based on FISH analysis with probe GNSB633 targeting this filamentous group (Sekiguchi et al., 1999).

Overall, our results based on T-RFLP, clone library and FISH analysis have revealed that the Desulfotomaculumrelated phylotypes (171 bp T-RF) were the main populations involved in the initial thermophilic fermentation of TA to give products further mineralized by the methanogenic counterpart. Likewise, other phylotypes representing different T-RFs observed in the T-RFLP profiles of sample D259 were also capable of TA degradation. Further studies on the enrichment and isolation of the thermophilic TAdegrading consortium could support this proposition, and would be useful to better understand the physiological role of the dominant bacterial groups in the thermophilic TAdegrading pathway and for process operation.

\section{ACKNOWLEDGEMENTS}

The authors thank Cindy Nakatsu, Wun Jern Ng and Aboubakar Ouattara for the critical comments on the study.

\section{REFERENCES}

Altschul, S. F., Madden, T. L., Schaffer, A. A., Zhang, J., Zhang, Z., Miller, W. \& Lipman, D. J. (1997). Gapped BLAST and PSI-BLAST: a new generation of protein database search programs. Nucleic Acids Res 25, 3389-3402.

Amann, R. I. (1995). In situ identification of micro-organisms by whole-cell hybridization with rRNA-targeted nucleic acid probes. In Molecular Microbial Ecology Manual, pp. 1-15. Edited by A. D. L. Akkerman, J. D. van Elsas \& F. J. de Bruijn. Dordrecht, The Netherlands: Kluwer.

Amann, R. I., Ludwig, W. \& Schleifer, K. H. (1995). Phylogenetic identification and in situ detection of individual microbial cells without cultivation. Microbiol Rev 59, 143-169.

Bouchez, T., Patureau, D., Dabert, P., Juretschko, S., Dore, J., Delgenes, P., Moletta, R. \& Wagner, M. (2000). Ecological study of a bioaugmentation failure. Environ Microbiol 2, 179-190.

Castro, H. F., Williams, N. H. \& Ogram, A. (2000). Phylogeny of sulfate-reducing bacteria. FEMS Microbiol Ecol 31, 1-9.

Cheng, S. S., Ho, C. Y. \& Wu, J. H. (1997). Pilot study of UASB process treating PTA manufacturing wastewater. Water Sci Technol 36(6-7), 73-82.

Daims, H., Brülh, A., Amann, R., Schleifer, K. H. \& Wagner, M. (1999). The domain-specific probe EUB338 is insufficient for the detection of all bacteria: development and evaluation of a more comprehensive probe set. Syst Appl Microbiol 22, 434-444.

Dojka, M. A., Hugenholtz, P., Haack, S. K. \& Pace, N. R. (1998). Microbial diversity in a hydrocarbon- and chlorinated-solventcontaminated aquifer undergoing intrinsic bioremediation. Appl Environ Microbiol 64, 3869-3877. 
El Mamouni, R., Guiot, S. R., Leduc, R. \& Costerton, J. W. (1995). Characterization of different microbial nuclei as potential precursors of anaerobic granulation. J Biotechnol 39, 239-249.

Embley, T. M., Finlay, B. J., Thomas, R. H. \& Dyal, P. L. (1992). The use of rRNA sequences and fluorescent probes to investigate the phylogenetic positions of the anaerobic ciliate Metopus palaeformis and its archaeobacterial endosymbiont. J Gen Microbiol 138, 1479-1487.

Fajardo, C., Guyot, J.-P., Macarie, H. \& Monroy, O. (1997). Inhibition of anaerobic digestion by terephthalic acid and its aromatic by products. Water Sci Technol 36(6-7), 83-90.

Hall, T. A. (1999). BioEdit: a user-friendly biological sequence alignment editor and analysis program for Windows 95/98/NT. Nucleic Acids Symp Ser 41, 95-98.

Hicks, R. E., Amann, R. I. \& Stahl, D. A. (1992). Dual staining of natural bacterioplankton with 4',6-diamidino-2-phenylindole and fluorescent oligonucleotide probes targeting kingdom-level $16 \mathrm{~S}$ rRNA sequences. Appl Environ Microbiol 58, 2158-2163.

Hugenholtz, P., Pitulle, C., Hershberger, K. L. \& Pace, N. R. (1998). Novel division level bacterial diversity in a Yellowstone hot spring. J Bacteriol 180, 366-376.

Imachi, H., Sekiguchi, Y., Kamagata, Y., Hanada, S., Ohashi, A. \& Harada, H. (2002). Pelotomaculum thermopropionicum gen. nov., sp. nov., an anaerobic, thermophilic, syntrophic propionateoxidizing bacterium. Int J Syst Evol Microbiol 52, 1729-1735.

Kane, M. D., Poulsen, L. K. \& Stahl, D. A. (1993). Monitoring the enrichment and isolation of sulfate-reducing bacteria by using oligonucleotide hybridization probes designed from environmentally derived 16S rRNA sequences. Appl Environ Microbiol 59, 682-686.

Kengen, S. W. M., Breidenbach, C. G., Felske, A., Stams, A. J. M., Schraa, G. \& de Vos, W. M. (1999). Reductive dechlorination of tetrachloroethene to cis-1,2-dichloroethene by a thermophilic anaerobic enrichment culture. Appl Environ Microbiol 65, 2312-2316.

Kleerebezem, R., Mortier, J., Hulshoff Pol, L. W. \& Lettinga, G. (1997). Anaerobic pretreatment of petrochemical effluents: terephthalic acid wastewater. Water Sci Technol 36(2-3), 237-248.

Kleerebezem, R., Hulshoff Pol, L. W. \& Lettinga, G. (1999a). Anaerobic degradation of phthalate isomers by methanogenic consortia. Appl Environ Microbiol 65, 1152-1160.

Kleerebezem, R., Hulshoff Pol, L. W. \& Lettinga, G. (1999b). The role of benzoate in anaerobic degradation of terephthalate. Appl Environ Microbiol 65, 1161-1167.

Kleerebezem, R., Ivalo, M., Hulshoff Pol, L. W. \& Lettinga, G. (1999c). High-rate treatment of terephthalate in anaerobic hybrid reactors. Biotechnol Prog 15, 347-357.

Kumar, S., Tamura, K., Jakobsen, I. B. \& Nei, M. (2001). MEGA2: molecular evolutionary genetics analysis software. Bioinformatics 17, $1244-1245$.

Liu, W. T., Marsh, T. L., Cheng, H. \& Forney, L. J. (1997). Characterization of microbial diversity by determining terminal restriction fragment length polymorphism of $16 \mathrm{~S}$ ribosomal DNA. Appl Environ Microbiol 63, 4516-4522.

Liu, W. T., Huang, C. L., Hu, J. Y., Soon, L. F., Ong, S. L. \& Ng, W. J. (2002). Denaturing gradient gel electrophoresis polymorphism for rapid $16 \mathrm{~S}$ rDNA clone screening and microbial diversity estimation. J Biosci Bioeng 93, 101-103.

Loy, A., Lehner, A., Lee, N., Adamczyk, J., Meier, H., Ernst, J., Schleifer, K. H. \& Wagner, M. (2002). Oligonucleotide microarray for $16 \mathrm{~S}$ rRNA gene-based detection of all recognized lineages of sulfate-reducing prokaryotes in the environment. Appl Environ Microbiol 68, 5064-5081.
Ludwig, W., Strunk, O., Westram, R. \& 29 other authors (2004). ARB: a software environment for sequence data. Nucleic Acids Res 32, 1363-1371.

Macarie, H. (2000). Overview of the application of anaerobic treatment to chemical and petrochemical wastewaters. Water Sci Technol 42(5-6), 201-214.

Macarie, H., Noyola, A. \& Guyot, J.-P. (1992). Anaerobic treatment of a petrochemical wastewater from a terephthalic acid plant. Water Sci Technol 25(7), 223-235.

Maidak, B. L., Cole, J. R., Lilburn, T. G. \& 9 other authors (2000). The RDP (Ribosomal Database Project) continues. Nucleic Acids Res 28, 173-174.

Manz, W., Amann, R., Ludwig, W., Vancanneyt, M. \& Schleifer, K. H. (1996). Application of a suite of $16 \mathrm{~S}$ rRNA-specific oligonucleotide probes designed to investigate bacteria of the phylum cytophagaflavobacter-bacteroides in the natural environment. Microbiology 142, 1097-1106.

Qiu, Y. L., Sekiguchi, Y., Imachi, H., Kamagata, Y., Tseng, I. C., Cheng, S. S., Ohashi, A. \& Harada, H. (2004). Identification and isolation of anaerobic, syntrophic phthalate isomer-degrading microbes from methanogenic sludges treating wastewater from terephthalate manufacturing. Appl Environ Microbiol 70, 1617-1626.

Raskin, L., Stomly, J. M., Rittmann, B. E. \& Stahl, D. A. (1994). Group-specific 16S rRNA hybridization probes to describe natural communities of methanogens. Appl Environ Microbiol 60, 1232-1240.

Schlötelburg, C. (2001). Mikrobielle Diversitat und Dynamik einer 1,2-Dichlorpropan dechlorierenden Mischkultur. PhD thesis, Humboldt-University, Berlin.

Schmid, M., Twachtmann, U., Klein, M., Strous, M., Juretschko, S., Jetten, M. S. M., Metzger, J. W., Schleifer, K.-H. \& Wagner, M. (2000). Molecular evidence for genus-level diversity of bacteria of catalyzing anaerobic ammonium oxidation. Syst Appl Microbiol 23, 93-106.

Sekiguchi, Y., Kamagata, Y., Syutsubo, K., Ohashi, A., Harada, H. \& Nakamura, K. (1998). Phylogenetic diversity of mesophilic and thermophilic granular sludges determined by $16 \mathrm{~S}$ rRNA gene analysis. Microbiology 144, 2655-2665.

Sekiguchi, Y., Kamagata, Y., Nakamura, K., Ohashi, A. \& Harada, H. (1999). Fluorescence in situ hybridization using $16 \mathrm{~S}$ rRNA-targeted oligonucleotides reveals localization of methanogens and selected uncultured bacteria in mesophilic and thermophilic sludge granules. Appl Environ Microbiol 65, 1280-1288.

Stahl, D. A. \& Amann, R. (1991). Development and application of nucleic acid probes. In Nucleic Acid Techniques in Bacterial Systematics, pp. 205-248. Edited by E. Stackebrandt \& M. Goodfellow. New York: Wiley.

Stickler, D. (1999). Biofilms. Curr Opin Microbiol 2, 270-275.

Stubner, S. \& Meuser, K. (2000). Detection of Desulfotomaculum in an Italian rice paddy soil by $16 \mathrm{~S}$ ribosomal nucleic acid analyses. FEMS Microbiol Ecol 34, 73-80.

Suresh, B., Davenport, B. \& Mavar, L. (2001). Dimethyl terephthalate (DMT) and terephthalic acid (TPA). In SRI International's Chemical Economics Handbook Program (http://ceh.sric.sri.com/ Public/Reports/).

van Lier, J. B. (1996). Limitation of thermophilic anaerobic wastewater treatment and the consequences for process design. Antonie Van Leeuwenhoek 69, 1-14.

van Lier, J. B., Rebac, S. \& Lettinga, G. (1997). High-rate anaerobic wastewater treatment under psychrophilic and thermophilic conditions. Water Sci Technol 35(10), 199-206. 
Wallner, G., Amann, R. \& Beisker, W. (1993). Optimizing fluorescent in situ hybridization with rRNA-targeted oligonucleotide probes for low cytometric identification of microorganisms. Cytometry 14, 136-143.
Wu, J. H., Liu, W. T., Tseng, I. C. \& Cheng, S. S. (2001). Characterization of microbial consortia in an anaerobic granular sludge system treating terephthalate. Microbiology 147, 373-382. 